\title{
PROPOSIÇÃO DE UM MÉTODO PARA MEDIR A CAPACIDADE DE PRODUÇÃO DE UM OBJETO PARAMÉTRICO POR UM SOFTWARE BIM $^{1}$
}

\author{
PROPOSING A METHOD TO MEASURE THE CAPACITY TO PRODUCE A \\ PARAMETRIC OBJECT ON A BIM SOFTWARE
}

\author{
João Alberto da Motta Gaspar \\ TI Lab \\ joaogaspar@tilab.com.br \\ Leonardo Manzione \\ Escola Politécnica da Universidade de São Paulo (POLI-USP) \\ leonardo@coordenar.com.br
}

\begin{abstract}
RESUMO
O acrônimo BIM é utilizado com diversos propósitos, conforme a livre interpretação sobre o tema; para categorizar um software como BIM, ou não, por exemplo. Os autores deste artigo ensinam, pesquisam e escrevem sobre BIM há muitos anos, e acreditam que devem ser desenvolvidos métodos para avaliar como os softwares realizam tarefas relacionadas a BIM. O objetivo foi propor e testar uma metodologia para verificar que qualificação teria um software BIM com relação à criação de objetos paramétricos. O método consistiu em simulações que permitiram a criação e teste de regras (usando o objeto paramétrico "Porta"), que deram origem a uma matriz dos recursos oferecidos por um binário ferramenta/software (sistema), para executar atividades relacionadas a este objeto. Os testes mostraram que os recursos oferecidos pelos sistemas variam muito; a partir da interpretação destes, foi possível estabelecer o Índice de Parametrização de Objetos em BIM (IPO-BIM), que sintetiza como um sistema lida com objetos BIM segundo os critérios definidos; recomenda-se que mais pesquisas sobre o assunto sejam feitas, para que haja mais informações qualificadas sobre softwares BIM para a comunidade.
\end{abstract}

Palavras-chave: BIM. Objetos paramétricos. IFC

\begin{abstract}
The acronym BIM is used for several purposes, according to the free interpretation of the theme; to categorize a software as BIM, or not, for example. In this article the authors, who have extensive security experience with BIM, believe that methods should be developed in order to evaluate how the software perform tasks related to BIM. The aim was to propose and test a methodology to verify which skills would a BIM software have regarding the creation of parametric objects. The method consisted of simulations that allowed the creation of tests using the parametric object "Door"), which gave rise to a matrix of features offered by a system (formed by a software/tool binary) to perform activities related to this object. Tests showed that the features offered by the systems vary widely; from the interpretation of these, it was possible to establish the BIM Parametrization Object Index (BIM-
\end{abstract}

\footnotetext{
${ }^{111}$ GASPAR, J.; MANZIONE, L. Proposição de um método para medir a capacidade de produção de um objeto paramétrico por um software BIM. In: ENCONTRO BRASILEIRO DE TECNOLOGIA DE INFORMAÇÃO E COMUNICAÇÃO NA CONSTRUÇÃO, 7., 2015, Recife. Anais... Porto Alegre: ANTAC, 2015.
} 
POI), which summarizes how a system handles BIM objects according to defined criteria; further development and updating of researches, in terms of its high-quality information, is recommended.

Palavras-chave: BIM. Parametric Objects. IFC.

\section{INTRODUÇÃO}

O acrônimo BIM é utilizado com os mais diversos propósitos; por exemplo, para categorizar um software de modelagem para arquitetura, ou engenharia, como BIM, ou não. Atualmente, um programa é considerado BIM a partir da livre interpretação (pela academia, pelo mercado, por profissionais e estudantes) do referencial teórico encontrado na bibliografia sobre o tema. Por esse motivo é comum encontrar, tanto na literatura especializada, quanto no dia-a-dia dos projetistas, discussões acaloradas sobre se há a necessidade de classificar softwares como BIM, ou não e, caso positivo, que requisitos um software deve ter para ser considerado BIM.

Para o desenvolvimento dessa pesquisa, os autores (o primeiro é um profissional em processo de candidatura a um mestrado; o coautor é doutor, e sua tese tem o BIM como assunto central) partem do pressuposto que só é possível inferir o quanto um programa é ou não BIM se houverem premissas bem definidas e métodos que possam ser testados e validados. Esse pressuposto foi estabelecido a partir da extensa experiência em ensino de ferramentas e processos orientados a sistemas de trabalho em BIM dos autores ${ }^{2}$. Se um usuário confiar apenas na palavra ou na opinião de especialistas ou vendors, sem metodologias que possam ser testadas e seus resultados, mensuráveis e comparáveis, pode ser induzido a fazer escolhas inadequadas para seus objetivos, investindo tempo e dinheiro demais (ou de menos) em uma solução que não atende às suas demandas; se torna, portanto, presa fácil para todo o tipo de BIM Wash (Succar, 2011). Uma vez que os principais softwares do mercado apresentam muitos recursos (de modelagem, quantificação, representação $2 \mathrm{D}$, colaboração, entre outros) seria praticamente impossível criar um único sistema de avaliação a respeito de quão BIM um programa é; portanto, se faz necessário desenvolver métodos para realizar tal avaliação.

\section{OBJETIVO}

A modelagem paramétrica de objetos é um dos pilares do BIM, e é um dos critérios mais frequentemente utilizados pela academia e pelo mercado como referência para caracterizálos como sendo softwares BIM. O objetivo, pois, foi estabelecer uma metodologia para verificar se, o quanto, e de que modo, um software para projeto arquitetônico em 3D (entre os que podem ser qualificados como softwares BIM de autoria) atende aos fundamentos teóricos que os qualificam quanto à sua capacidade de criação de objetos BIM paramétricos.

\section{METODOLOGIA}

O método proposto consistiu em simulações que permitiram a criação de testes e regras, que por sua vez deram origem a uma matriz que organiza os dados a respeito dos recursos tecnológicos oferecidos ao usuário, por um software, para executar atividades típicas relacionadas a objetos paramétricos. Os critérios utilizados para desenvolvê-la estão fundamentados nas definições sobre modelagem paramétrica, estabelecidas por diversos pesquisadores $\mathrm{BIM}^{3}$. Para que o escopo do estudo fosse corretamente definido, e os objetivos da pesquisa, avaliados, os pesquisadores adotaram o seguinte roteiro:

\footnotetext{
2 Gaspar (2012, 2013, 2014, 2015) e Manzione (2013).

${ }^{3}$ Lee, Sacks e Eastman (2005), Eastman, Teicholz, Sacks e Liston (2011), Davis (2013) e NBS (2014).
} 
- Revisão bibliográfica para a escolha da definição sobre objeto paramétrico BIM

- Escolha do objeto paramétrico BIM a ser testado

- Escolha dos softwares a serem testados

- Características geométricas e não-geométricas a serem avaliadas no objeto BIM de referência

- Atividades relacionadas ao uso do objeto BIM de referência

- Criação e teste da matriz

\subsection{Revisão bibliográfica para encontrar a definição mais adequada sobre o que é um objeto paramétrico BIM}

Para definir o objeto de estudo, foi feita uma revisão bibliográfica a respeito do que originalmente era aceito como modelagem paramétrica em softwares para projetos, até as mais novas e importantes definições sobre o que é um objeto BIM paramétrico.

Uma das definições mais conhecidas e aceitas por pesquisadores e profissionais em todo o mundo é a que está no livro The BIM Handbook (Eastman et al, 2011). Os autores afirmam que o conceito objeto paramétrico é crucial para entender o BIM, e que são consideradas ferramentas BIM de autoria aquelas que permitem a criação de modelos constituídos por estes objetos. No entanto, observou-se que algumas das premissas apontadas nos tópicos 1.4.1 e 1.4.2 deste livro são de tal forma tão restritivas quanto à definição de que seja um software BIM, (quanto ao do que seria um objeto paramétrico BIM) que nenhum dos softwares apontados como plataformas BIM no tópico 2.6.1, consegue, na prática, cumprir todos os requisitos ipsis litteris ${ }^{4}$ (Eastman et al, 2011).

A questão da inviabilidade de se operar, na prática, um modelo completamente paramétrico já era apontada em Technical Notes from experiences and studies in using Parametric and BIM architectural software (Smith, 2007). Em sua defesa de doutorado, Daniel Davis (2013), parafraseando o The BIM Handbook, traz a seguinte ressalva, grifada em itálico e que não consta da frase original 5 :

Aqueles que advogam a favor do BIM defendem que "O BIM reduz o retrabalho (o que cria flexibilidade) ao ser constituído por um repositório central de dados a partir de onde as representações gráficas são desenhadas; altere os dados uma vez e teoricamente tudo é atualizado" (Davis, 2013, p.8).

Fez-se necessário, a partir deste ponto, pesquisar outras definições a respeito do que é um objeto paramétrico BIM, para dar o andamento adequado e correto à pesquisa. Entre diversas definições pesquisadas, entendeu-se que o manual NBS BIM Object Standard v1.2, atualmente apresenta a mais adequada.

\footnotetext{
${ }^{4}$ No item 1.4.1, a mais complicada de se obter por todos os programas elencados como BIM no item 2.6.1, é aquela que afirma que o "modelo de construção é composto por dados consistentes e não redundantes, de modo que alterações nos dados de um componente são refletidos em todas as vistas e montagens onde este aparece" (tradução nossa). A consistência e não redundância das informações geométricas e não-geométricas dependem muito mais da habilidade e cuidado do especialista BIM do que da solução tecnológica.

No item 1.4.2, que trata dos requisitos que um objeto deve apresentar para ser considerado como BIM, existem definições que, no mínimo, podem ser consideradas hiperbólicas: a segunda, que diz que a "geometria é integrada de modo não redundante e não permite inconsistências" (tradução nossa), assim como os exemplos dados para ilustrar a terceira definição, não funcionam como regra geral, de modo automático, em nenhum dos softwares citados pelos autores, pois dependem do uso correto das ferramentas.

5 Tradução e grifo em itálico nossos.
} 
O objeto BIM deverá ter geometria paramétrica conforme o suporte oferecido pela plataforma BIM, e onde for conveniente, a geometria será travada e alinhada a elementos de referência apropriados, como planos, linhas, níveis e pontos" (NBS, 2014, p.24, tradução nossa).

\subsection{Escolha do objeto paramétrico BIM a ser testado}

Os objetos paramétricos em uma plataforma BIM não possuem apenas um modo de se comportar; portanto, foi preciso estudar como estes podem ser categorizados, para que objeto-teste fosse corretamente escolhido. Após revisão bibliográfica específica para esse assunto, observou-se que, como regra geral, um objeto paramétrico BIM pode ser qualificado a partir do ponto de vista de seu comportamento (Lee et al, 2005) e de como é instanciado no ambiente de modelagem BIM (Tabelas 1 e 2 e Figura 1):

Tabela 1 - Classificação de um objeto de acordo com seu comportamento no ambiente BIM

\section{Comportamento Descrição}

\begin{tabular}{ll}
\hline Hospedeiro & $\begin{array}{l}\text { Tem sua geometria e dados associados automaticamente alterados sempre que recebe ou } \\
\text { deixa de receber um objeto hóspede; ao ser movimentado, copiado, duplicado, apagado, } \\
\text { etc., tais alterações automaticamente impactam o(s) objeto(s) hóspede(s) }\end{array}$ \\
\hline Hóspede & É todo aquele capaz de ser conectado ao hospedeiro, como descrito acima \\
\hline Neutro & É todo objeto que não hospeda, nem é hospedado por nenhum outro \\
\hline
\end{tabular}

Fonte: Elaborado pelos autores

Tabela 2 - Classificação de um objeto de acordo com o método de instanciamento

\begin{tabular}{ll}
\hline Instanciamento & Descrição \\
\hline Pontual & $\begin{array}{l}\text { Possui apenas um ponto de referência declarado no ambiente BIM. Objetos como colunas, } \\
\text { portas, janelas, equipamentos sanitários e mobiliário são, geralmente, pontuais (embora seja } \\
\text { possível criá-los, dependendo do contexto e utilidade, como objetos lineares ou poligonais) }\end{array}$ \\
\hline Linear & $\begin{array}{l}\text { Objeto que é geometricamente instanciado por dois pontos de referência. Como exemplo, } \\
\text { podemos citar vigas e segmentos de paredes }\end{array}$ \\
\hline Poligonal & $\begin{array}{l}\text { Objeto instanciado por três ou mais pontos de referência. A poligonal pode ser aberta, sendo } \\
\text { suporte para paredes conectadas, por exemplo, ou fechada, permitindo a criação de lajes, } \\
\text { forros e coberturas, entre outros objetos }\end{array}$ \\
\hline
\end{tabular}

Fonte: Elaborado pelos autores

Figura 1 - Objetos paramétricos, seu comportamento e método de instanciamento

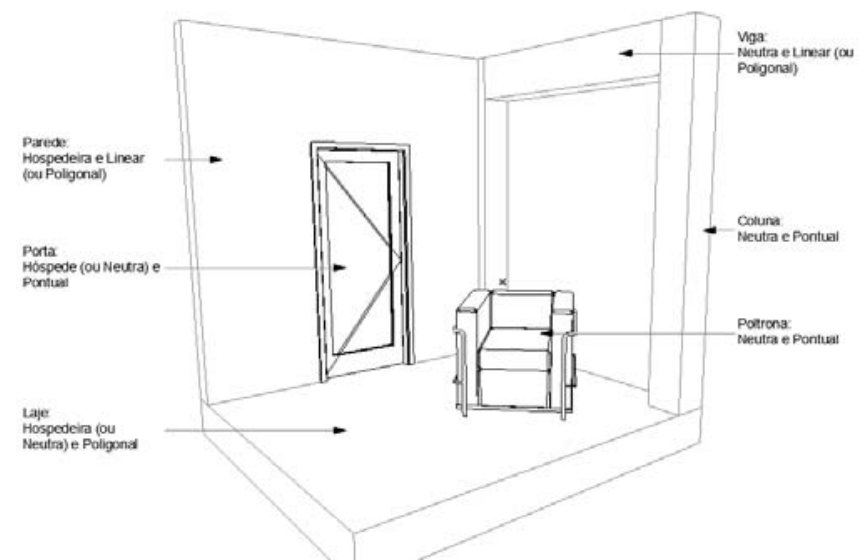

Fonte: Elaborado pelos autores 
Feita a classificação, chegou-se à conclusão que o objeto Porta é o que melhor atende aos objetivos da pesquisa, pois atua como hóspede ou neutro, dependendo do contexto, da intenção do projetista e da capacidade da plataforma BIM. Para este estudo, definiu-se por avaliar a Porta como tendo comportamento neutro: desta forma isolam-se diferentes e prováveis resultados que os testes teriam quando da relação da Porta com hospedeiros, dado que nem todos os softwares se comportam de modo idêntico com relação à hospedagem. Além disso, sendo a Porta um objeto pontual, avaliações mais controladas poderiam ser feitas, uma vez que objetos instanciados linear ou poligonalmente permitem interpretações diversas, que poderiam contribuir para a perda de foco da pesquisa.

\subsection{Escolha dos softwares a serem testados}

São muitos os softwares capazes de criar objetos paramétricos BIM de acordo com a definição de referência desta pesquisa (NBS, 2014), e todos oferecem mais de uma ferramenta para criá-los; basicamente o que as diferenciam (tanto entre os programas, quando dentro de um mesmo programa) é o conhecimento prévio que o usuário tem (ou não) em geometria, matemática e em linguagens de programação. Para orientar o recorte tecnológico que norteou o estudo, as ferramentas foram divididas em cinco categorias ${ }^{6}$, identificadas de $\mathrm{A}$ a $\mathrm{E}$, como mostra a Tabela 3:

Tabela 3 - Categorização das ferramentas que podem criar um objeto Porta de acordo com nível de conhecimento prévio do usuário (NCPU)

\begin{tabular}{lll}
\hline Cat. & NCPU & Descrição da ferramenta adequada ao NCPU \\
\hline A & Nenhum & $\begin{array}{l}\text { Cria objetos usando regras e interfaces definidas pelo software, em que } \\
\text { "uma instância de um objeto é criada através de uma interface orientada } \\
\text { ao usuário, onde este determina novos valores em um conjunto de } \\
\text { parâmetros pré-definidos" (Lee et al, 2006, tradução nossa). }\end{array}$ \\
\hline B & $\begin{array}{l}\text { Conhecimento básico de } \\
\text { funções e expressões }\end{array}$ & $\begin{array}{l}\text { Método de produção de objetos em que existe um conjunto de regras } \\
\text { pré-definidas pelo software, e que suportam parâmetros e geometrias } \\
\text { matemáticas }\end{array}$ \\
\hline que serão criadas pelo usuário (Boeykens, 2012, p. 457).
\end{tabular}

Fonte: Elaborado pelos autores

Foi determinado que apenas as categorias A B e $C$ seriam avaliadas no estudo, por serem as de uso mais comum entre os projetistas. Foram testadas ferramentas capazes de criar um objeto Porta em diversos softwares, para definir quais seriam utilizados para criar e testar a matriz. As Figuras 2 a 6 mostram telas dos SISTEMAS escolhidos para análise (por serem, de acordo com as poucas pesquisas sobre o assunto, os mais utilizados em todo o mundo $^{7}$ em projetos de arquitetura), com o objetivo de ilustrar a relações deles com as categorias apresentadas na Tabela 4.

\footnotetext{
${ }^{6}$ É importante frisar que as categorizações não sugerem, de forma alguma, que uma ferramenta ou método é capaz de criar objetos melhores do que outros.

${ }^{7}$ Foram usados como referência os levantamentos feitos por Crowd (2015) e NBS (2015).
} 
Tabela 4 - Categorização dos SISTEMAS de acordo com a Tabela 3

\begin{tabular}{lllll}
\hline Cat. (Fig. Ex.) & Ano & Fabricante & Software & Ferramenta \\
\hline A (2) & 1984 & Graphisoft & ArchiCAD & Paramétrico Porta \\
\hline A (2) & 1985 & N. Vectorworks & Vectorworks & Paramétrico Porta \\
\hline A (2) & 2000 & Autodesk & Revit & Paramétrico Porta \\
\hline B (3) & 2000 & Autodesk & Revit & Editor de Famílias \\
\hline B (3) & 2004 & Bentley & Microstation & Parametric Cell Studio (PCS) \\
\hline $\mathbf{C ~ ( 4 ) ~}$ & 2008 & Trimble & SketchUp & Componente Dinâmico \\
\hline D (5) & 2003 & Bentley & Microstation & Generative Components \\
\hline D (5) & 2007 & McNeel & Rhino & Grasshopper \\
\hline D (5) & 2011 & Autodesk & Revit & Dynamo \\
\hline E (6) & 1982 & Autodesk & AutoCAD & AutoLISP \\
\hline E (6) & 1996 & Graphisoft & ArchiCAD & GDL \\
\hline E (6) & 1998 & N. Vectorworks & Vectorworks & VectorScript \\
\hline E (6) & 2004 & Trimble & SketchUp & Ruby \\
\hline E (6) & 2007 & Autodesk & Revit & VB.NET e C\#
\end{tabular}

Fonte: Elaborado pelos autores

Figura 2 - Exemplos de SISTEMAS Categoria A: Porta Paramétrica do ArchiCAD e Vectorworks

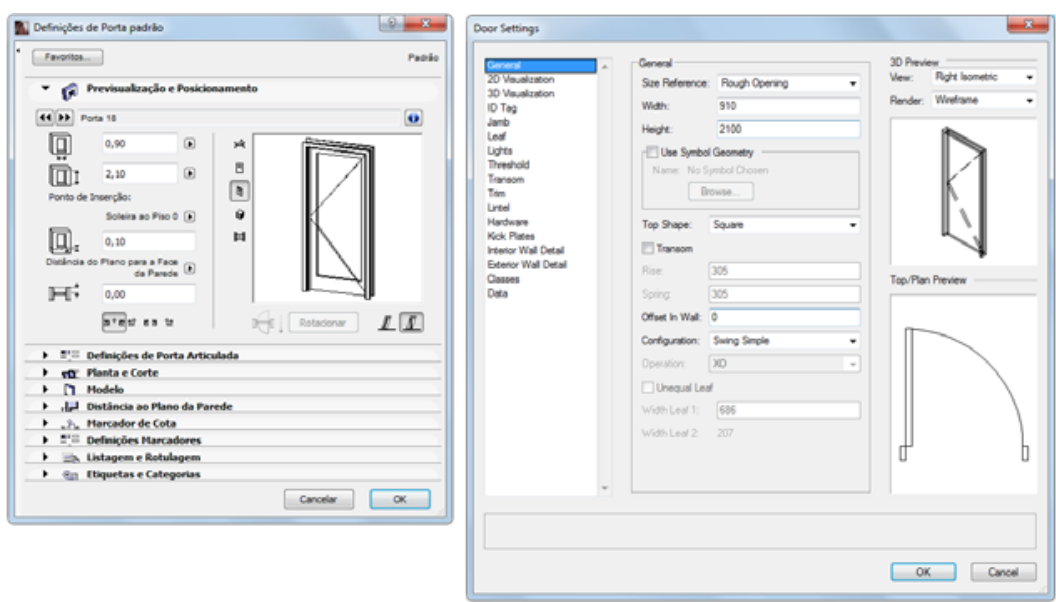

Fonte: Elaborado pelos autores

Figura 3 - Exemplos de SISTEMAS Categoria B: Editor de Famílias do Revit e PCS, Microstation
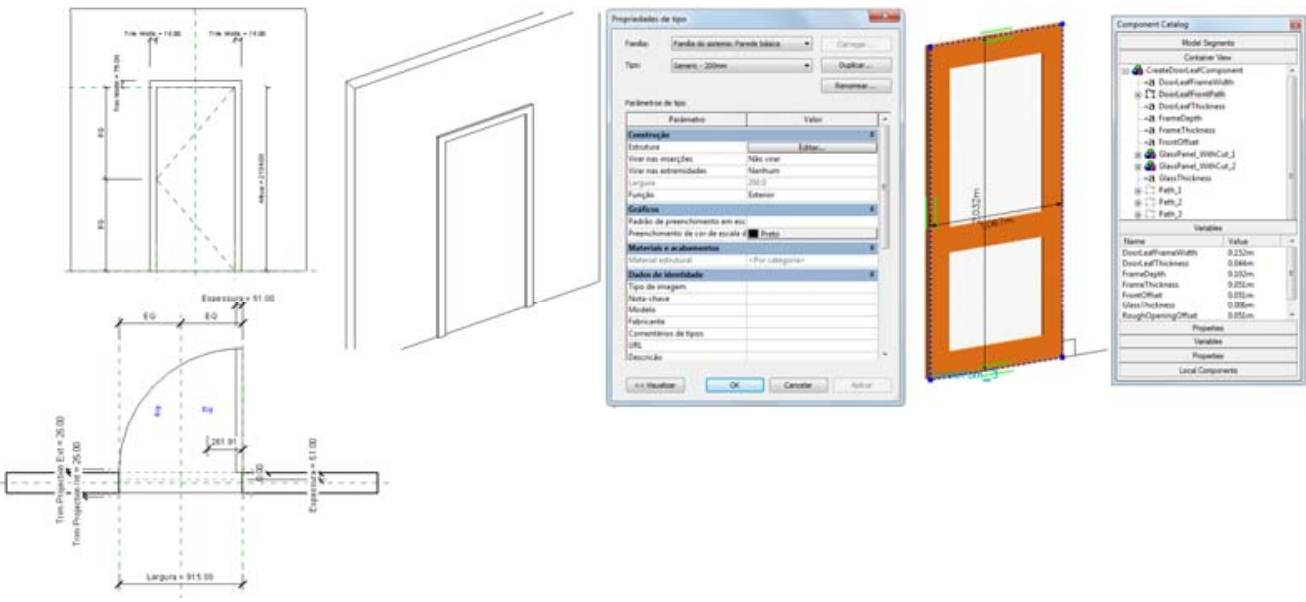

Fonte: Elaborado pelos autores 
Figura 4 - Exemplos de SISTEMA Categoria C: Componente Dinâmico, SketchUp

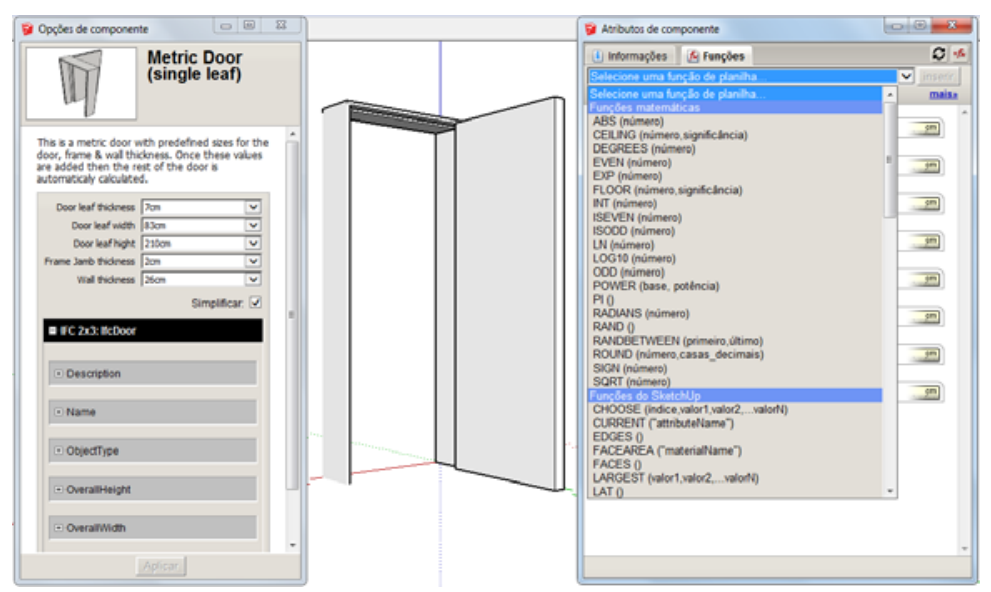

Fonte: Elaborado pelos autores, usando o objeto programado por Corrêa (2013)

Figura 5 - Exemplo de SISTEMA Categoria D: Grasshopper, Rhino

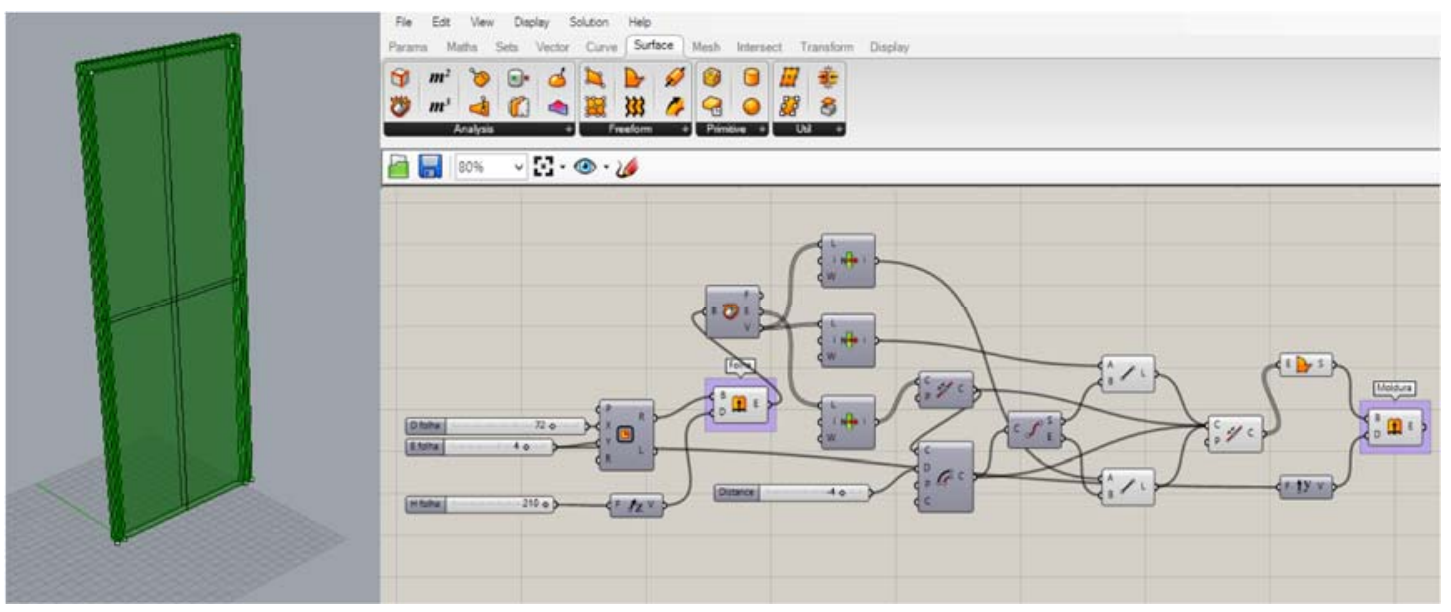

Fonte: Elaborado pelos autores, usando o objeto programado por Machado (2015)

Figura 6 - Exemplo de SISTEMA Categoria E: VectorScript, Vectorworks
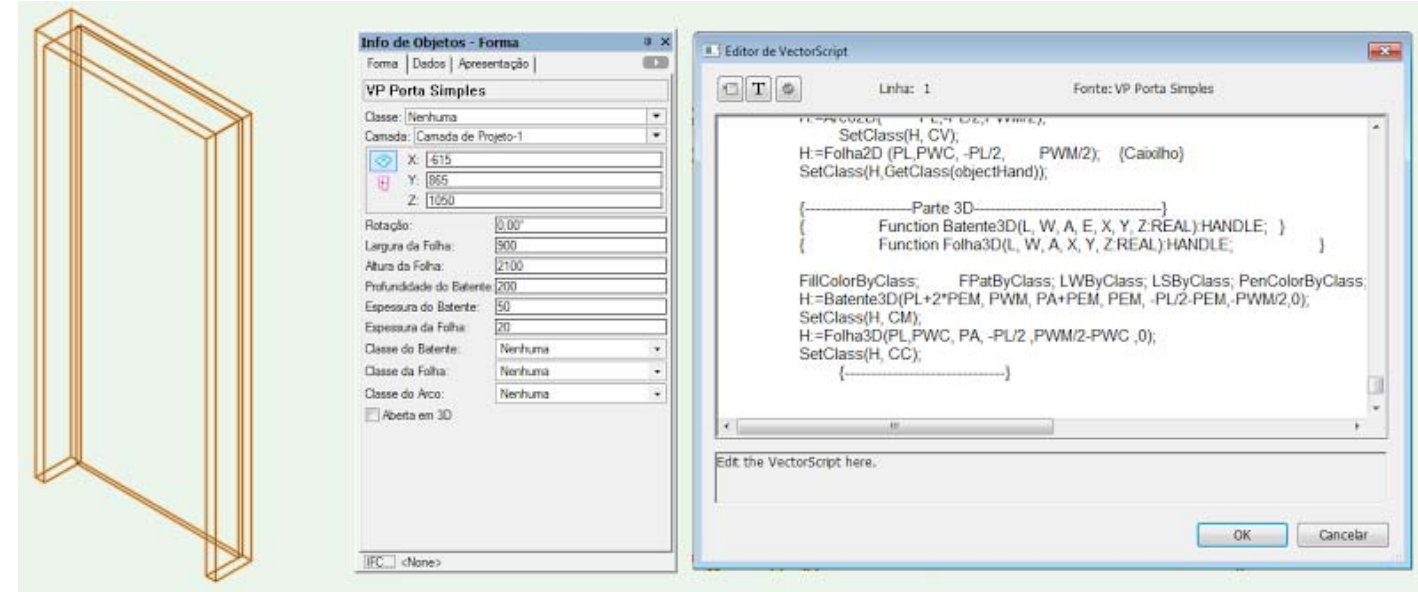

Fonte: Elaborado pelos autores, usando o objeto programado por Villares (2001) 
Chegou-se, então, à definição dos cinco SISTEMAS que foram utilizados na pesquisa8: Componentes Dinâmicos (SketchUp) ${ }^{9}$, Paramétrico Porta (ArchiCAD), Editor de famílias (Revit), Paramétrico Porta (Vectorworks) e Parametric Cell Studio - PCS (Microstation).

\section{ELABORAÇÃO DOS CRITÉRIOS PARA A CRIAÇÃO DA MATRIZ}

Nesta etapa foram discriminadas as operações que determinam a criação do objeto-teste, e quais atividades estão relacionadas à essa criação. Um sistema de pontuação foi proposto para avaliar a qualidade do relacionamento entre operações e atividades. Assim, foi possível estabelecer o formato da matriz, apresentada no item 5 - RESULTADOS.

\subsection{0perações geométricas, não-geométricas e atividades a serem avaliadas}

Para estudo, o objeto-teste teve suas características funcionais separadas em cinco operações: Representação 2D (R2D), Modelo 3D (M3D), Interação Paramétrica Interna (IPI), Interação Paramétrica Externa (com outros objetos paramétricos) (IPE) e capacidade de armazenamento de dados não-geométricos (ADNG) ${ }^{10}$. As atividades relacionadas ao manejo de cada operação do objeto-teste são três: CRIAR um objeto novo, EDITAR uma instância de um objeto, e criar a versão IFC do objeto-teste e testar sua integridade. Esta última atividade, porém, só está relacionada a duas das operações consideradas acima. A Tabela 5 sintetiza o relacionamento entre as operações e as atividades, qualificando-as como existentes ou não-existentes.

Tabela 5 - Existência de relacionamento entre operações e atividades

\begin{tabular}{llllll}
\hline \multicolumn{7}{c}{ Operações } & & & & \\
\hline Atividades & R2D & M3D & IPI & IPE & ADNG \\
\hline CRIAR um novo objeto & Existente & Existente & Existente & Existente & Existente \\
\hline EDITAR uma instância & Existente & Existente & Existente & Existente & Existente \\
\hline Integridade do objeto IFC & Não-existente & Existente & Não-existente & Não-existente & Existente \\
\hline
\end{tabular}

Fonte: Elaborado pelos autores

\subsection{Atividades relacionadas ao uso do objeto}

Para completar a matriz, foi necessário criar um sistema de pontuação que pretende as qualificar as atividades (Tabelas 6 e 7), indicando se o SISTEMA dispõe dos recursos necessários e, caso positivo, como tais recursos se apresentam ao usuário no que diz respeito à sua funcionalidade e obtenção de resultados. A pontuação é numérica e dividida em intervalos de 100 de modo a deixar espaço para atualizações nos critérios, que poderão se situar entre os atuais.

\footnotetext{
${ }^{8}$ A ferramenta de objetos paramétricos do Revit, dada a sua característica técnica, só pode ser avaliada em conjunto com seu respectivo par, o Editor de Famílias.

${ }^{9}$ A aceitação do SketchUp como ferramenta BIM de autoria ainda é polêmica e relativamente recente; porém, funcionalidades incluídas a partir da versão 2014 tornam o componente dinâmico capaz de ser enquadrado dentro dos critérios de objeto paramétrico, de acordo com NBS (2014), Banks (2014), Taylor-Foster (2014), Khemlani (2014), Rumbelow (2014) e Frausto-Robledo (2014).

10 A definição destes critérios tem origem em estudos baseados em Prakoso (2010), Gaspar (2012), Fitzpatrick (2013), Thompson (2014) e Graphisoft (2015).
} 
Tabela 6 - Critérios de pontuação do SISTEMA sobre sua capacidade de realizar as operações relacionadas às atividades CRIAR e EDITAR

\begin{tabular}{|c|c|c|c|c|c|}
\hline \multicolumn{6}{|c|}{ Critérios de pontuação para as atividades CRIAR e EDITAR } \\
\hline Operações & $\mathbf{0}$ & 100 & 200 & 300 & 400 \\
\hline R2D & $\begin{array}{l}\text { Não é capaz } \\
\text { de produzir } \\
\text { a operação }\end{array}$ & Não se aplica & $\begin{array}{l}\text { Oferece uma } \\
\text { parametrização } \\
\text { rudimentar }\end{array}$ & $\begin{array}{l}\text { Geração de } \\
\text { elementos 2D a } \\
\text { partir de } \\
\text { predefinições; } \\
\text { limitação das } \\
\text { variações }\end{array}$ & $\begin{array}{l}\text { Editor paramétrico que } \\
\text { permite a geração de } \\
\text { elementos 2D e 3D } \\
\text { sem limitação de } \\
\text { variações }\end{array}$ \\
\hline M3D & $\begin{array}{l}\text { Não é capaz } \\
\text { de produzir } \\
\text { a operação }\end{array}$ & Não se aplica & $\begin{array}{l}\text { Oferece uma } \\
\text { parametrização } \\
\text { rudimentar }\end{array}$ & $\begin{array}{l}\text { Geração de } \\
\text { elementos 3D a } \\
\text { partir de } \\
\text { predefinições; } \\
\text { limitação das } \\
\text { variações }\end{array}$ & $\begin{array}{l}\text { Editor paramétrico que } \\
\text { permite a geração de } \\
\text { elementos } 2 \mathrm{D} \text { e 3D } \\
\text { sem limitação de } \\
\text { variações }\end{array}$ \\
\hline IPI & $\begin{array}{l}\text { Não é capaz } \\
\text { de produzir } \\
\text { a operação }\end{array}$ & Não se aplica & $\begin{array}{l}\text { Realizada por } \\
\text { interface } \\
\text { simplificada de } \\
\text { programação }\end{array}$ & $\begin{array}{l}\text { Relações } \\
\text { paramétricas são } \\
\text { pré-estabelecidas }\end{array}$ & $\begin{array}{l}\text { Editor paramétrico que } \\
\text { permite o } \\
\text { estabelecimento de } \\
\text { quaisquer relações }\end{array}$ \\
\hline IPE & $\begin{array}{l}\text { Não é capaz } \\
\text { de produzir } \\
\text { a operação }\end{array}$ & $\begin{array}{l}\text { Existe apenas entre } \\
\text { algumas classes de } \\
\text { objetos; não é } \\
\text { possível propor } \\
\text { outras interações }\end{array}$ & $\begin{array}{l}\text { Existe entre } \\
\text { diversas classes de } \\
\text { objetos; não é } \\
\text { possível propor } \\
\text { outras interações }\end{array}$ & $\begin{array}{l}\text { É possível propor } \\
\text { interações entre } \\
\text { diferentes classes, } \\
\text { de modo } \\
\text { simplificado }\end{array}$ & $\begin{array}{l}\text { Editor paramétrico que } \\
\text { permite o } \\
\text { estabelecimento de } \\
\text { quaisquer relações }\end{array}$ \\
\hline ADNG & $\begin{array}{l}\text { Não é capaz } \\
\text { de produzir } \\
\text { a operação }\end{array}$ & $\begin{array}{l}\text { Preenchimento } \\
\text { manual de apenas } \\
\text { um ou dois campos, } \\
\text { e não é possível } \\
\text { criar novos }\end{array}$ & $\begin{array}{l}\text { Preenchimento } \\
\text { manual de todos os } \\
\text { campos; } \\
\text { possibilidade de } \\
\text { criar novos; } \\
\text { glossário limitado } \\
\text { e/ou insuficiente }\end{array}$ & $\begin{array}{l}\text { Alguns campos } \\
\text { com preenchimento } \\
\text { automático; é } \\
\text { possível criar } \\
\text { novos; glossário } \\
\text { limitado e/ou } \\
\text { insuficiente }\end{array}$ & $\begin{array}{l}\text { Alguns campos com } \\
\text { preenchimento } \\
\text { automático; é possível } \\
\text { criar novos; glossário } \\
\text { adequado }\end{array}$ \\
\hline
\end{tabular}

Fonte: Elaborado pelos autores

Tabela 7 - Critérios de pontuação do SISTEMA sobre sua capacidade de realizar as operações relacionadas à atividade IFC

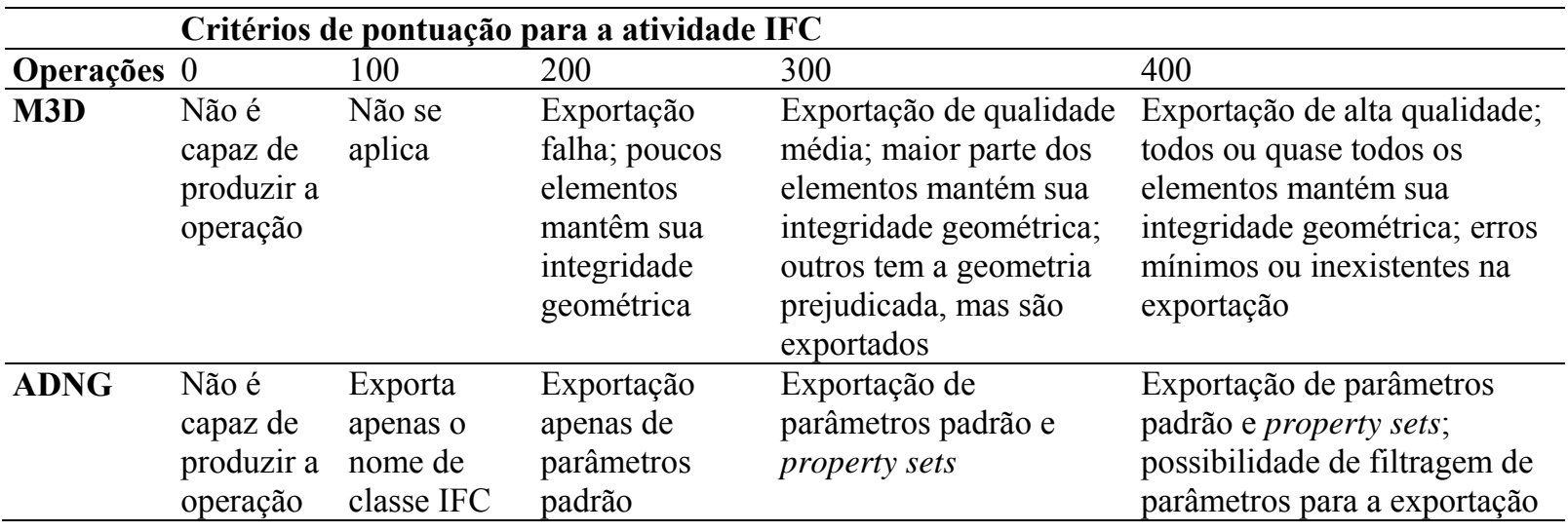

Fonte: Elaborado pelos autores

\section{RESULTADOS}

A seguir apresentamos a Tabela 8, matriz que avalia os recursos tecnológicos oferecidos por um SISTEMA no que diz respeito às operações e atividades relacionadas ao objeto- 
teste. Ela é constituída pelo cruzamento entre operações e atividades promovidas (Tabela 5); para cada cruzamento é dada uma pontuação, de acordo com o estabelecido nas Tabelas 6 e 7.

Tabela 8 - Matriz para avaliação de um SISTEMA com relação ao objeto Porta

\begin{tabular}{lllllll}
\hline SISTEMA & Operação & & & & & \\
\hline Atividade & R2D & M3D & IPI & IPE & ADNG & $\begin{array}{l}\text { TOTAL por Atividade } \\
\text { (IPO-BIM-A) }\end{array}$ \\
\hline CRIAR & 0 a 400 & 0 a 400 & 0 a 400 & 0 a 400 & 0 a 400 & 0 a 2000 \\
\hline EDITAR & 0 a 400 & 0 a 400 & 0 a 400 & 0 a 400 & 0 a 400 & 0 a 2000 \\
\hline IFC & --- & 0 a 400 & 0 a 400 & --- & --- & 0 a 800 \\
\hline $\begin{array}{l}\text { Total por } \\
\begin{array}{l}\text { Operação } \\
\text { (IPO-BIM-O) }\end{array}\end{array}$ & 0 a 800 & 0 a 1200 & 0 a 800 & 0 a 800 & 0 a 1200 & 0 a $4800-$ TOTAL \\
(IPO-BIM)
\end{tabular}

Fonte: Elaborado pelos autores

Para verificar se a matriz seria eficiente para cumprir o objetivo proposto, foram feitos testes com os SISTEMAS escolhidos (item 3.3). Todas as atividades e operações foram realizadas, e a pontuação obtida, anotada, como mostrado na Tabela 9.

Tabela 9 - Avaliação dos SISTEMAS em relação à capacidade de produção do objeto Porta

\begin{tabular}{|c|c|c|c|c|c|c|c|}
\hline \multirow{6}{*}{$\begin{array}{l}\text { Componentes } \\
\text { Dinâmicos } \\
\text { (SketchUp) }\end{array}$} & \multicolumn{4}{|c|}{ Operação } & \multirow[b]{2}{*}{ IPE } & \multirow[b]{2}{*}{ ADNG } & \multirow[b]{2}{*}{ IPO-BIM-A } \\
\hline & Atividade & R2D & M3D & IPI & & & \\
\hline & CRIAR & 200 & 200 & 200 & 0 & 200 & 800 \\
\hline & EDITAR & 200 & 200 & 200 & 0 & 200 & 800 \\
\hline & IFC & --- & 400 & --- & --- & 200 & 600 \\
\hline & IPO-BIM-O & 400 & 800 & 400 & 0 & 600 & 2200 (IPO-BIM) \\
\hline \multirow{6}{*}{$\begin{array}{l}\text { Porta } \\
\text { Paramétrica } \\
\text { (ArchiCAD) }\end{array}$} & & \multicolumn{3}{|c|}{ Operação } & & & \\
\hline & Atividade & R2D & M3D & IPI & IPE & ADNG & IPO-BIM-A \\
\hline & CRIAR & 300 & 300 & 300 & 100 & 400 & 1400 \\
\hline & EDITAR & 300 & 300 & 300 & 100 & 400 & 1400 \\
\hline & IFC & --- & 400 & --- & --- & 400 & 800 \\
\hline & IPO-BIM-O & 600 & 1000 & 600 & 200 & 1200 & 3600 (IPO-BIM) \\
\hline \multirow{6}{*}{$\begin{array}{l}\text { Editor de } \\
\text { Famílias } \\
\text { (Revit) }\end{array}$} & & \multicolumn{3}{|c|}{ Operação } & & & \\
\hline & Atividade & R2D & M3D & IPI & IPE & $\mathrm{ADNG}$ & IPO-BIM-A \\
\hline & CRIAR & 400 & 400 & 400 & 200 & 400 & 1800 \\
\hline & EDITAR & 300 & 300 & 400 & 200 & 400 & 1500 \\
\hline & IFC & --- & 400 & --- & --- & 400 & 800 \\
\hline & IPO-BIM-O & 700 & 1100 & 700 & 400 & 1200 & 4100 (IPO-BIM) \\
\hline \multirow{6}{*}{$\begin{array}{l}\text { Porta } \\
\text { Paramétrica } \\
\text { (Vectorworks) }\end{array}$} & & \multicolumn{3}{|c|}{ Operação } & & & \\
\hline & Atividade & R2D & M3D & IPI & IPE & $\mathrm{ADNG}$ & IPO-BIM-A \\
\hline & CRIAR & 300 & 300 & 300 & 100 & 300 & 1300 \\
\hline & EDITAR & 300 & 300 & 300 & 100 & 300 & 1300 \\
\hline & IFC & --- & 400 & --- & --- & 300 & 700 \\
\hline & IPO-BIM-O & 600 & 1000 & 600 & 200 & 900 & 3300 (IPO-BIM) \\
\hline \multirow{6}{*}{$\begin{array}{l}\text { Parametric } \\
\text { Cell Studio } \\
\text { (AECOsim) }\end{array}$} & & \multicolumn{3}{|c|}{ Operação } & & & \\
\hline & Atividade & R2D & M3D & IPI & IPE & $\mathrm{ADNG}$ & IPO-BIM-A \\
\hline & CRIAR & 400 & 400 & 400 & 300 & 400 & 1900 \\
\hline & EDITAR & 300 & 300 & 300 & 300 & 400 & 1600 \\
\hline & IFC & --- & 400 & --- & --- & 1200 & 800 \\
\hline & IPO-BIM-O & 700 & 1100 & 700 & 600 & 1200 & 4300 (IPO-BIM) \\
\hline
\end{tabular}

Fonte: Elaborado pelos autores 


\section{CONCLUSÕES}

Considerou-se que a matriz demonstrou ser eficiente para tornar mais clara a identificação dos pontos fortes e fracos dos SISTEMAS analisados, de acordo com os critérios estabelecidos e descritos neste artigo, no que diz respeito ao escopo da pesquisa. Foi possível estabelecer um índice, denominado Índice de Parametrização de Objetos em BIM (IPO-BIM), que reúne os pontos obtidos por cada SISTEMA, relacionados à sua capacidade de oferecer recursos para a produção de um objeto Porta, para cada operação e atividade relacionada; este índice ainda pode ser subdividido em indicadores por atividade (IPO-BIMA) e operação (IPO-BIM-O).

Sabe-se, contudo, que existem SISTEMAS que não foram considerados neste estudo, não foram analisados objetos hospedeiros e hóspedes, assim como não foram feitas avaliações sobre objetos instanciados de modo linear ou poligonal. Percebeu-se que há espaço para novos tipos de operações e atividades a serem qualificadas, e espera-se que a metodologia apresentada neste estudo seja capaz de receber de modo adequado os novos estudos comparativos, caso sejam realizados. Como resultado indireto, é possível estabelecer uma espécie de ranqueamento dos SISTEMAS, de acordo com o método e critérios estabelecidos. No entanto, optou-se por não fazer uma tabela indicativa de qualquer tipo de ranking, por não ser parte do escopo da pesquisa. De todo o modo, os pesquisadores concluem que o método apresentado é válido, pois contribui para aumentar a qualidade das informações a respeito do que é oferecido pela indústria de software para a comunidade.

\section{REFERÊNCIAS}

BANKS, J. SketchUp Pro 2014 and IFC: welcome to the new world of BIM. Shoegnome, 2014. Disponivel em: <http://www.shoegnome.com/2014/04/13/sketchup-pro-2014-and-ifc/>. Acesso em: 13 abr. 2014.

BERGIN, M. S. A Brief History of BIM. Style of Design, 2012. Disponível em: $<$ http://www.styleofdesign.com/architecture/a-brief-history-of-bim-michael-s-bergin/>. Acesso em: 7 dez. 2012.

GUDNASON, G.; Scherer, R. (Ed.). eWork and eBusiness in Architecture, Engineering and Construction. London: Taylor \& Francis Group / CRC Press, 2012.

CORRÊA, A. M. Metric Door (single leaf). GetPro Componentes Dinâmicos para SketchUp. São Paulo: ProBooks 2015.

CROWD, G. Compare Best CAD \& PLM Software. Chicago, 2015. Disponível em: <https://www.g2crowd.com/categories/cad-plm/?order=scale_score>. Acesso em: 20 mai. 2015.

DAVIS, D. Modelled on Software Engineering: Flexible Parametric Models in the Practice of Architecture. 234p. (Tese Doutorado). School of Architecture and Design, RMIT, Melbourne, Australia, 2013.

EASTMAN, C. et al. BIM Handbook: A Guide to Building Information Modeling for Owners, Managers, Designers, Engineers and Contractors. 2ed., Wiley, 2011.

FITZPATRICK, D. PCS on PCS: A Practical Combat Session on Parametric Cell Studio. Mid-America CADD Summer Conference. Overland Park, Kansas, 2013.

FRAUSTO-ROBLEDO, A. Product Review: Trimble SketchUp Pro 2014. Architosh, 2014. Disponível em: <http://architosh.com/2014/08/product-review-trimble-sketchup-pro-2014/>. Acesso em: 25 ago. 2014. 
GASPAR, J. ArchiCAD passo a passo. 1ed. São Paulo: ProBooks, 2014.

Revit passo a passo - Volume I. 1ed. São Paulo: ProBooks, 2015.

SketchUp Pro 2013 passo a passo. 1ed. São Paulo: ProBooks, 2013.

Vectorworks passo a passo. 1ed. São Paulo: ProBooks, 2012.

GRAPHISOFT. Graphic Interface Panel for a Door. Help Center Graphisoft, Budapeste, Hungria, 2015. Disponível em: <http://helpcenter.graphisoft.com/guides/archicad-18-int-reference-guide/userinterface-reference/tool-settings-dialog-boxes/graphical-interface-panel-for-a-door/>. Acesso em: 20 mai. 2015.

JANSSEN, P. H. T.; CHEN, K. W. Visual Dataflow Modelling: A Comparison of Three Systems. CAAD Futures 2011. Liège, Belgium, 2011.

KHEMLANI, L. SketchUp Pro 2014. AEC Bytes, 2014. Disponível em: <http://www.aecbytes.com/review/2014/SketchUpPro2014.html>. Acesso em: 28 ago. 2014.

LEE, G.; SACKS, R.; EASTMAN, C. M. Specifying parametric building object behavior (BOB) for a building information modeling system. Automation in Construction, v. 15, n. 6, 2006. Disponível em: <http://www.sciencedirect.com/science/article/pii/S0926580505001445>. Acesso em: 20 mai. 2015.

MACHADO, C. A. Jr. Porta Paramétrica em Rhino e Grasshopper: ProBooks, 2015.

MANZIONE, L. Proposição de uma estrutura conceitual de gestão do processo de projeto colaborativo com o uso do BIM. 2013. Tese (Doutorado em Engenharia de Construção Civil e Urbana) - Escola Politécnica, Universidade de São Paulo, São Paulo, 2013. Disponível em: <http://www.teses.usp.br/teses/disponiveis/3/3146/tde-08072014-124306/>. Acesso em: 2015-08-07.

NBS. NBS BIM Object Standard. NBS National BIM library, Newcastle upon Tyne, UK,: 44p., 2014.

NBS National BIM Report 2015, NBS National BIM library, Newcastle upon Tyne, UK, 2015.

PRAKOSO, E. Creating Revit Family: Door. CAD Notes, Depok, Indonesia, 2010. Disponível em: <http://www.cad-notes.com/creating-revit-family-door/>. Acesso em: 14 fev. 2010.

RUMBELOW, M. Bargain Basement BIM. SketchUp 2014 now has native IFC. ThinkBIM, 2014. Disponível em: <https://revitall.wordpress.com/2014/03/01/bargain-basement-bim/>. Acesso em: 1 mar. 2014.

SMITH, R. Technical Notes from experiences and studies in using. Parametric and BIM architectural software. p. 6, 2007. Disponível em: <http://www.vbtllc.com/images/VBTTechnicalNotes.pdf>. Acesso em: 4 mar. 2007.

SUCCAR, B. Understanding BIM Wash: a primer for clients and service providers. Revit Technology Conference - Australasia. Jupiter Gold Coast, 2011.

TAYLOR-FOSTER, J. SketchUp 2014 Incorporates BIM Capabilities. ArchiDaily, 2014. Disponível em: <http://www.archdaily.com/?p=484579>. Acesso em: 9 mar. 2014.

THOMPSON, P. Lesson 11: Multiple animations (part 3). The SketchUp Dynamic Components Tutorial, 2014. Disponível em: <http://sketchupdcs.blogspot.com.br/2014/04/lesson-11-multipleanimations-part-3.html>. Acesso em: 22 abr. 2014.

VILLARES, A. B. d. A. VP Porta Simples. VectorPlus: ProBooks, 2001. 